\title{
Weakening of rainfall intensity on wet soils over the wet Asian monsoon region using a high-resolution regional climate model
}

\author{
Hiroshi G. Takahashi ${ }^{1,2^{*}}$ (D) and Jan Polcher ${ }^{3}$
}

\begin{abstract}
This study estimated the sensitivity of rainfall characteristics (rainfall amount, rainfall frequency, rainfall intensity, and rainfall extremes based on 30-min intervals) to land-surface conditions over Southeast Asia, which has a wet land surface during the rainy season. To obtain the regional difference in sensitivity and simulate basic cloud-precipitation systems, we used a high-resolution regional climate model. To extract the systematic signals of sensitivity and exclude random errors, a series of six sensitivity experiments, which were driven by a reanalysis dataset and the observed sea surface temperature (SST), were conducted over the Indochina Peninsula. In our experiments, soil moisture was prescribed at $0.20,0.25,0.30,0.35,0.40$, and $0.45 \mathrm{~m}^{3} \mathrm{~m}^{-3}$ over the whole domain and during the whole calculation period. More experiments would allow us to divide the responses into systematic signals and random noise. The slope of a meteorological variable as a function of the six prescribed soil moisture values was defined as the sensitivity. It was found that the sensitivity of rainfall frequency to soil moisture was positive overall, whereas the sensitivity of rainfall intensity was negative overall, although evapotranspiration (sensible heat flux) increased (decreased) in a manner similar to the increase in soil moisture over the whole domain. The sensitivity of rainfall amount to an increase in soil moisture was dependent on the location. This implies that the response of rainfall characteristics to soil moisture is not simple, suggesting that changes in rainfall characteristics are not solely determined by evapotranspiration. In addition, the sensitivity of rainfall characteristics displayed remarkable regional characteristics. The characteristics described above were noticeable over the inland flat plains. We also discussed the mechanism in the response of rainfall characteristics to soil moisture. The coupling of an increase in water vapor in the planetary boundary layer and a decrease of sensible heat flux can explain the response. The increase in water vapor in the planetary boundary layer was associated with a reduction of the development of deep convections and an increase of boundary layer clouds.
\end{abstract}

Keywords: Rainfall characteristics, Asian monsoon, Land surface condition, Soil moisture, Regional climate model, Soil-rainfall feedback

\section{Introduction}

The land-atmosphere coupling is a significant component of the climate system. Changes in surface conditions can alter the regional climate. In terms of the effects of human activities on regional climate changes, changes in land-surface conditions by human activities,

\footnotetext{
*Correspondence: hiroshi3@tmu.ac.jp

'Department of Geography, Tokyo Metropolitan University, 1-1

Minamioosawa, Hachioji, Tokyo 192-0397, Japan

${ }^{2} J a p a n$ Agency for Marine-Earth Science and Technology, Yokohama

236-0001, Japan

Full list of author information is available at the end of the article
}

such as deforestation and urbanization, and conversion to cropland, are major drivers.

Changes in land-surface conditions, such as soil moisture, can change the balances of water and energy at the Earth's surface. Many previous studies using global and regional climate models have examined the realistic or potential impacts of deforestation on the regional and global climates (e.g., Henderson-Sellers and Gornitz (1984); Shukla et al. (1990); Polcher and Laval (1994); Pielke (2001); Takata et al. (2009)). There is a general agreement that deforestation leads to reduced rainfall 
and evaporation and increased surface temperature in regions where soil moisture changes have occurred. The land-atmosphere coupling strength has been investigated in terms of the improvement of seasonal forecasts; for example, Koster et al. (2004) found that the key soil moisture regions for seasonal forecasts are semi-arid regions (boundary regions between wet and dry regions). However, these previous studies used coarse-resolution climate models.

Recent studies have used high-resolution observations or high-resolution regional climate models to explore the feedback between soil moisture and precipitation. Taylor et al. (2012) showed that a dry surface resulted in a large amount of rainfall over the drier regions of West Africa. Taylor (2015) demonstrated the role of the horizontal non-uniformity of soil moisture on an initiation of convection over Europe. These results were supported by the direct observation of the mesoscale circulations driven by heterogeneous soil moisture conditions (Taylor et al. 2007). As a climate modeling study, Froidevaux et al. (2014) suggested that a dry soil patch activates an initiation of convection and a wet soil patch generates precipitation due to a convectively unstable condition. The importance of surface flux heterogeneity was also examined by a large-eddy simulation (Rochetin et al. 2017). In addition, Tuttle and Salvucci (2016) suggested the different response of precipitation to soil moisture due to the background regional aridity. Thus, understanding of feedback over drier regions has gradually improved on mesoscale, whereas over wetter regions it is still limited. Over wetter regions, a few numerical studies using a high-resolution climate model (Takahashi et al. 2010; Sugimoto and Takahashi 2017) have investigated changes in rainfall due to changes in soil moisture. This study focused on the wetter Asian monsoon region, because of a lack of previous studies with a focus on wetter climates.

It is well known that global warming can induce an increase in rainfall amount and a decrease in weaker rainfall events (e.g., IPCC 2013), which suggests a change in rainfall characteristics. The changes in rainfall characteristics and extremes are significant issues associated with climate change, and with changes in floods and droughts. Changes in soil moisture greatly modify the budgets of energy and water at the surface, which can result in changes in rainfall characteristics. Previous numerical studies over wet regions (Takahashi et al. 2010; Sugimoto and Takahashi 2017) considered changes in rainfall characteristics due to regional changes in soil moisture. An increase in soil moisture tends to result in a weakening of rainfall intensity over the wet Asian monsoon region. The effect of an increase in soil moisture on rainfall frequency has been found to differ markedly among regions. Although many numerical studies have shown the simulated evidence, it is generally difficult to obtain observational evidence. For example, Ono and Takahashi (2016) and Takahashi (2016) showed a similar tendency of the effect of land-surface conditions on rainfall intensity over the wet Asian monsoon region from observed datasets. However, more studies are required to fully understand the mechanisms of these responses.

For example, a wetter surface increases evaporation and water vapor in the lower troposphere and decreases sensible heating in turn the height of planetary boundary layer. This may increase the boundary layer clouds. However, more sensible heating can increase the height of planetary boundary layer and may increase rainfall intensity when the lower troposphere is sufficiently wet. Because both mechanisms are possible, more studies are necessary to understand the impact of soil moisture on precipitation characteristics.

Moreover, regional characteristics of the sensitivity of clouds and precipitation to soil moisture need to be evaluated to understand the impact of soil moisture changes by human activities, because human-induced land-surface changes are generally smaller than the resolution of global climate models (GCMs), i.e., typically $100 \mathrm{~km}$. In addition, it is very difficult to understand the physical process of the impact of soil moisture on regional climate using GCMs because of their coarse horizontal resolution. Moreover, only a high-resolution regional climate simulation can include realistic orographic effects.

The main aim of this study is to understand the sensitivity of rainfall characteristics to soil moisture over wet Asian monsoon region. We focus on the wet Southeast Asian monsoon region where our understanding of the impact of soil moisture on rainfall characteristics remains inadequate. This study tries to understand the impact of soil moisture on rainfall characteristics according to a framework of one-way impacts from soil moisture to the atmosphere on a fine horizontal scale to better understand the physical processes involved. "Methods/experimental" section describes the model setting and data used in this study. The "Result" section presents our results regarding the response of rainfall characteristics to soil moisture. Finally, the mechanisms of the response of rainfall characteristics to soil moisture are discussed in the "Discussion" section, and our conclusions are presented in the "Conclusion" section.

\section{Methods/experimental Model setting}

This study used a high-resolution regional climate model to determine the sensitivity of rainfall characteristics to land surface conditions. First, the spatial scale of the changes in land use due to human activities was generally less than $100 \mathrm{~km}$. In addition, we examined regional differences of sensitivity associated with topography and 
land-sea distribution. Second, because this study focused on the sensitivity of rainfall characteristics, a basic rainfall system should be simulated. Particularly over the tropical Asian monsoon region, convective rainfall systems with a diurnal precipitation cycle are dominant (e.g., Takahashi et al. 2010).

For the purposes of our study, we used a nonhydrostatic regional climate model, the Advanced Research Weather Research and Forecasting (WRF) modeling system (Skamarock et al. 2008) Version 3.4.1. First, we conducted control (CTL) experiments. We used the atmospheric conditions from the ERA-Interim product (Dee et al. 2011; http://www.ecmwf.int/en/research/ climate-reanalysis/era-interim) of the European Centre for Medium-Range Weather Forecasts (ECMWF) and sea surface temperature (SST) from the Optimum Interpolation Sea Surface Temperature, version 2 (OISST2; Reynolds et al. 2002; http://www.esrl.noaa.gov/psd/data/ gridded/data.noaa.oisst.v2.html) as the initial and boundary conditions. To investigate the impact of soil moisture in a simple manner, we used monthly mean SST data. The monthly SST data were linearly interpolated with time. The interpolated SST data were prescribed every $6 \mathrm{~h}$. In the CTL experiments, the soil moisture values were predicted. In the main experiments, soil moisture was fixed at a specific value (see "Sensitivity experiments under the prescribed soil moisture" section).

The Southeast Asian monsoon region, which has a relatively wet climate, was selected as the computational target region. The model domain is shown in Fig. 1. A portion of the Indochina Peninsula in Southeast Asia has some of the heaviest precipitation levels of any area in the world (e.g., Takahashi 2016). We conducted 2-month time-slice experiments for the first half of the summer monsoon season (Takahashi and Yasunari 2006) extending from June to July (JJ). We selected the 2 months of June

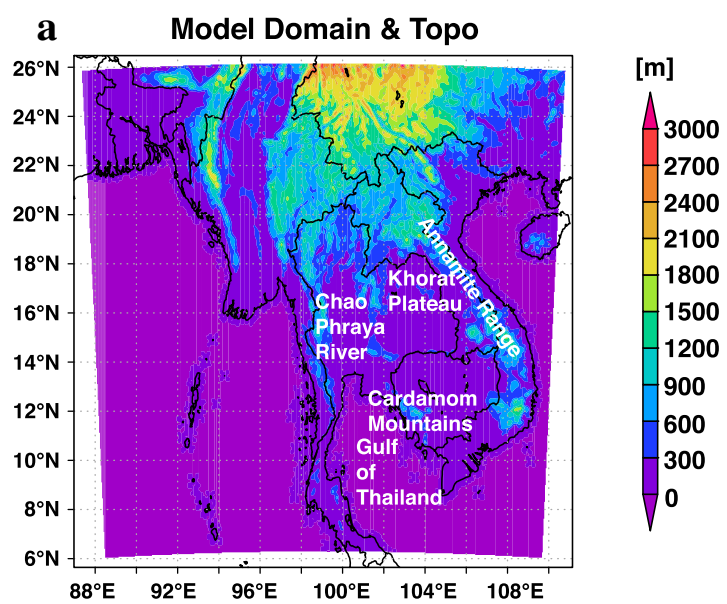

b LU_index (Mixed Forest/Water)

c Green Fraction (Const=60\%:Iand)

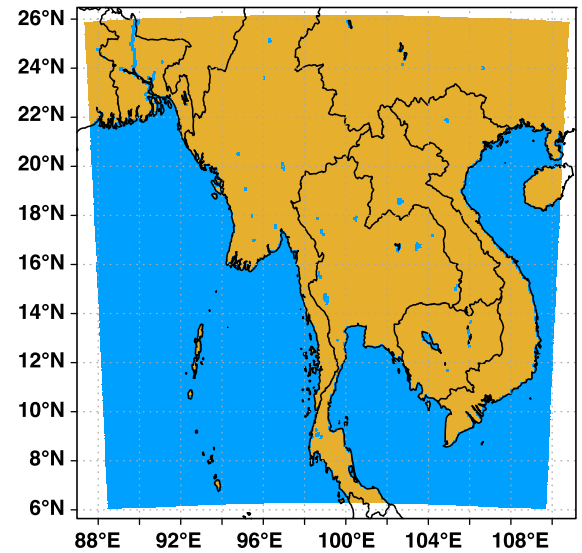

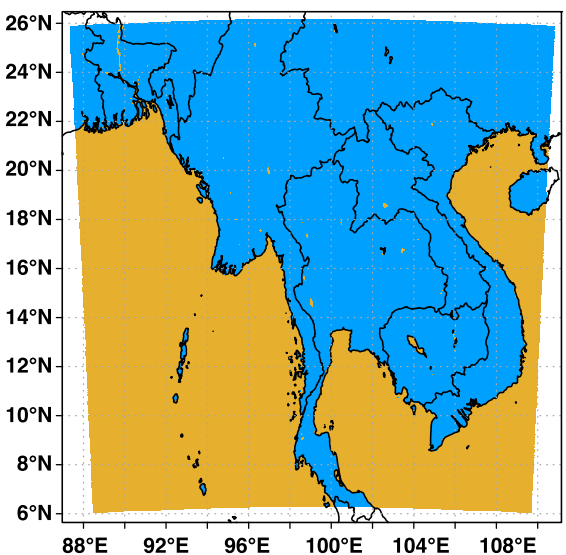

Fig. 1 a Study area, geographical names and topography in Domain 1. b Landuse index used in this simulation. For simplicity, all land uses were converted to a specific land use category except for water bodies. c Spatial distribution of the vegetation fraction, which was used in the land surface model (LSM). Differences in this parameter can affect the Bowen ratio under the same near-surface atmospheric, and soil moisture conditions. For simplicity, all values over land were unified to 0.6 , which indicated that $60 \%$ of the grid area was covered by vegetation 
2010 and July 2010 as the simulation periods to represent a typical summer monsoon year. We also conducted the same experiments during JJ of 2011 and 2012. Even under the atmospheric conditions in the flood year of 2011 (e.g., Takahashi et al. 2015), the basic results were the same as in 2010. In addition, because 2012 was a typical monsoon year, the results were basically the same as in 2010. Thus, we only show the results for 2010 in this paper. These simulation periods extended from 1 June 2010 to 1 August 2010, 1 June 2011 to 1 August 2011, and 1 June 2012 to 1 August 2012. The first 2 days of each simulation were a spin-up period and were not included in the analysis.

The model configuration details are provided here. As mentioned above, to resolve basic rainfall systems, $8-\mathrm{km}$ horizontal spacing was used. Due to the huge computational cost, a relatively low resolution was selected. We confirmed that the 8-km spacing experiments could capture the basic rainfall systems over the tropics, such as the diurnal rainfall cycles over the Southeast Asian monsoon region (Sugimoto and Takahashi 2016). The domain has 27 terrain-following vertical levels. Moreover, because cumulus convective parameterization controls not only convective systems but also the related atmospheric circulation through thermodynamic effects, sensitivity experiments may depend almost exclusively on cumulus convective parameterization. Because test simulations with cumulus convective parameterization showed an unrealistic spatial distribution in rainfall amount over and around the Indochina Peninsula, we did not apply cumulus convective parameterization in the domain, referred to as the previous studies on the warm seasons when convective rainfall is predominant (e.g., Takahashi et al. 2009); Takahashi et al. (2015); Sugimoto and Takahashi (2016); Dado and Takahashi (2017)). The Mellor-YamadaJanjić planetary boundary layer scheme (Janjić 1994), the single-moment six-class microphysics scheme (Hong and Lim 2006), the unified Noah land surface model (LSM; Chen and Dudhia 2001), and the Rapid Radiative Transfer Model for GCM application (RRTMG) longwave and short-wave radiation schemes (Iacono et al. 2008) were used.

The unified Noah LSM has one canopy layer and four soil layers down to $2 \mathrm{~m}$, with the root zone in the upper 1 $\mathrm{m}$. The surface skin temperature was determined by a surface energy balance equation for the combined groundvegetation surface. The total evapotranspiration was the sum of the direct evaporation $\left(E_{d i r}\right)$ from the top soil layer, evaporation of precipitation intercepted by the canopy $\left(E_{c}\right)$, and transpiration by the canopy $\left(E_{t}\right) . E_{d i r}$ and $E_{c}$ were calculated by a Penman-based energy balance approach that included a stability-dependent aerodynamic resistance. The canopy resistance was calculated with empirical equations (Jacquemin and Noilhan 1990). The dry wilting points over this study region were approximately from 0.01 to $0.14 \mathrm{~m}^{3} \mathrm{~m}^{-3}$ as volumetric soil moisture content. The saturation volumetric soil moisture content was less than $0.45 \mathrm{~m}^{3} \mathrm{~m}^{-3}$. These values were dependent on the dominant soil type of the grid point.

To analyze the sensitivity of rainfall characteristics to land-surface conditions, we recorded every $30 \mathrm{~min}$ only for the accumulated rainfall amount. The other simulated meteorological variables were recorded every $3 \mathrm{~h}$.

\section{Observed dataset}

To evaluate the spatial pattern of simulated rainfall over the Southeast Asian monsoon region, this study used the Tropical Rainfall Measuring Mission (TRMM) 3B42 (Huffman et al. 2007) dataset from 1998 to present. The dataset was partly evaluated by rain gauge observations. We used the data in 2010, 2011, and 2012. The spatial resolution of TRMM3B42 is $0.25^{\circ}$ in longitude and latitude. Although other rain-gauge-based datasets are available, their quality is dependent on the input dataset. Because few observations are used over mountain ranges, the performance of rain-gauge-based datasets is highly dependent on a complementary algorithm used in the dataset. Thus, we used the TRMM 3B42 dataset in this study.

\section{Sensitivity experiments under the prescribed soil moisture}

To isolate the one-way impact of soil moisture on regional climate including rainfall characteristics through changes in the Bowen ratio, we conducted a series of sensitivity experiments. In general, most previous studies have estimated the sensitivity of soil moisture from two experiments under different soil moisture conditions, for example, soil moisture values as fixed at $0.05 \mathrm{~m}^{3} \mathrm{~m}^{-3}$ and $0.45 \mathrm{~m}^{3} \mathrm{~m}^{-3}$ over the target area of interest. The differences in the simulated meteorological variables between the two experiments can be considered to correspond to the sensitivity of the simulated meteorological variables to soil moisture in many studies. However, the chaotic nature of climate systems introduces random noise, which makes the estimation of sensitivity more difficult. More experiments would allow us to divide the responses into systematic signals and random noise. Thus, we conducted six experiments to estimate systematic sensitivity. The number of experiments was determined based on the upper limit of computational and data-storage costs. An explanation of how to calculate the sensitivity from the six experiments is given in "Prescribed soil moisture sensitivity (PSMsens)" section.

A series of six experiments were conducted with prescribed soil moisture values. Volumetric soil moisture was prescribed at $0.20,0.25,0.30,0.35,0,40$, and 0.45 $\mathrm{m}^{3} \mathrm{~m}^{-3}$ as the volumetric soil moisture content over the whole domain and during the whole calculation period, where the experiments were referred to as SM020, SM025, SM030, SM035, SM040, and SM045, respectively. 
The four soil layers in the LSM were prescribed at the same value. The aim was to determine the atmospheric response to the soil moisture through the changes in the Bowen ratio. Note that the feedback of rainfall to soil moisture was switched off to isolate the one-way impact of soil moisture on the atmosphere. Over wet climate regimes, the shortage of soil moisture for evapotranspiration is not important, unlike in dry climate regimes.

A soil moisture value of $0.45 \mathrm{~m}^{3} \mathrm{~m}^{-3}$ is typical just after a major rainfall event, and $0.20 \mathrm{~m}^{3} \mathrm{~m}^{-3}$ is typical for the dry season or a rainfall break over the target region of this study. Thus, a soil moisture range of $0.2 \mathrm{~m}^{3} \mathrm{~m}^{-3}$ to 0.45 $\mathrm{m}^{3} \mathrm{~m}^{-3}$ was used, which is typical of a relatively wet Asian monsoon region.

In addition, for simplicity, we unified the land use index as "Mixed forest" in the unified Noah LSM of the WRF except for water bodies (Fig. 1b). Moreover, the fraction of vegetation coverage was fixed at $60 \%$ over the whole domain except for water bodies (Fig. 1c), which meant that $60 \%$ of the grid area was covered by vegetation. This setting can yield the spatially uniform impact of soil moisture on the atmosphere except for the impact of topography and the land-sea contrast.

\section{Prescribed soil moisture sensitivity (PSMsens)}

To determine the mean changes in rainfall characteristics, we calculate the prescribed soil moisture sensitivity (PSMsens) using the following steps. First, monthly mean values of meteorological variables including rainfall characteristics were calculated. The definitions of rainfall characteristics are provided in "The definition of rainfall characteristics" section. For the meteorological variables, excluding the rainfall characteristics, a monthly value was simply averaged from 3-h outputs for a June-July (JJ) mean value in each grid for each experiment. For rainfall characteristics, we calculated a monthly value based on 30-min outputs. At the spatial scale, we transformed the original output (8- $\mathrm{km}$ horizontal resolution) into $0.1^{\circ}$ in longitude and latitude. The effect of the transformation on analysis results was negligibly small.

Second, we calculated the slopes of meteorological variables, including the rainfall characteristics in each grid as a function of the prescribed soil moisture from the JJ averages of the six sensitivity experiments (SM020, SM025, SM030, SM035, SM040, and SM045). The slopes quantified the increase or decrease in meteorological variables due to changes in the soil moisture. A positive (negative) PSMsens indicates an increase (decrease) in a meteorological variable with an increase in soil moisture. In the figures, we unified the PSMsens values to yield into a change per 0.1-volumetric-soil-moisture increase. These values were based on the prescribed ranges of soil moisture. We defined this PSMsens because the importance of soil moisture shortage for evapotranspiration is small over wet climate regimes.

In the estimation of slopes, to reduce the adverse effects of outliers, we adapted the Theil-Sen method, which is based on direct estimation of the median of pairwise slopes. This is because the estimation of a slope is generally strongly affected by outliers when the least square method is applied. In this step, we also calculated the Pearson correlation coefficient in each grid between meteorological variables and the prescribed soil moisture values. The correlation coefficients were used to evaluate whether an estimated slope was systematic or not. We plotted only the systematic sensitivities, which were statistically significant at the $90 \%$ significance level (four degrees of freedom), determined by Student's $t$ test. From here, PSMsens indicates the slope of a meteorological variable as a function of soil moisture.

\section{The definition of rainfall characteristics}

To understand the sensitivity of rainfall characteristics, we defined rainfall frequency, rainfall intensity, and rainfall extremes, based on the previous studies of numerical experiments and analysis of observed datasets (e.g., Sugimoto and Takahashi 2017; Takahashi 2016). The four parameters: rainfall amount, rainfall frequency, rainfall intensity, and rainfall extremes, were calculated from the simulated 30-min rainfall amount. The high temporal resolution of the output of numerical experiments in this study allowed a more accurate estimation of rainfall characteristics than $1 \mathrm{~h}$ or $3 \mathrm{~h}$ outputs. The total rainfall amount was defined as the accumulated rainfall amount over the analysis period of 2 months. The rainfall frequency was calculated from the rainfall occurrence, which was determined as a grid-scale $30 \mathrm{~min}$ rainfall amount was larger than $0.05 \mathrm{~mm} 30 \mathrm{~min}^{-1}\left(0.1 \mathrm{~mm} \mathrm{~h}^{-1}\right)$. The rainfall frequency was defined as the number of grid-scale rainfall occurrences divided by the total number of $30 \mathrm{~min}$ simulation slots, expressed as a percentage. We confirmed that our conclusion was unchanged when we used different threshold values. The rainfall intensity was calculated as the total rainfall amount divided by the rainfall frequency. This can also be also considered a conditional rainfall rate. In addition, we defined the 30-min rainfall extreme as the maximum 30-min rainfall amount within the simulation period at each grid, to better understand the changes in rainfall intensity due to the changes in land-surface conditions. To determine the rainfall extremes, we used 2832 30 -min samples ( 59 days $\times 24 \mathrm{~h} \times 2(30 \mathrm{~min})$ ) for each grid.

Changes in rainfall amount can be derived from changes in rainfall frequency and rainfall intensity. To identify the contributions of the changes in rainfall frequency $R_{F}$ and rainfall intensity $R_{I}$ to rainfall amount $R_{A}$, we conducted an order estimation. Rainfall amount was defined as follows: 


$$
R_{A}=R_{F} R_{I}
$$

The changes in rainfall amount, rainfall frequency, and rainfall intensity were expressed as $\delta R_{A}, \delta R_{F}$, and $\delta R_{I}$, respectively.

$$
R_{A}+\delta R_{A}=\left(R_{F}+\delta R_{F}\right)\left(R_{I}+\delta R_{I}\right)
$$

Typical values of $\delta R_{F}$ and $\delta R_{I}$ range from 0.01 to 0.1 . Thus, $\delta R_{F} \delta R_{I}$ is negligibly small. Therefore, the changes in rainfall amount may be rewritten as follows:

$$
\delta R_{A} \approx R_{F} \delta R_{I}+\delta R_{F} R_{I}
$$

or

$$
\frac{\delta R_{A}}{R_{A}} \approx \frac{\delta R_{F}}{R_{F}}+\frac{\delta R_{I}}{R_{I}}
$$

Thus, the changes in rainfall amount can be approximated as a simple linear combination, which can be expressed as a percentage.
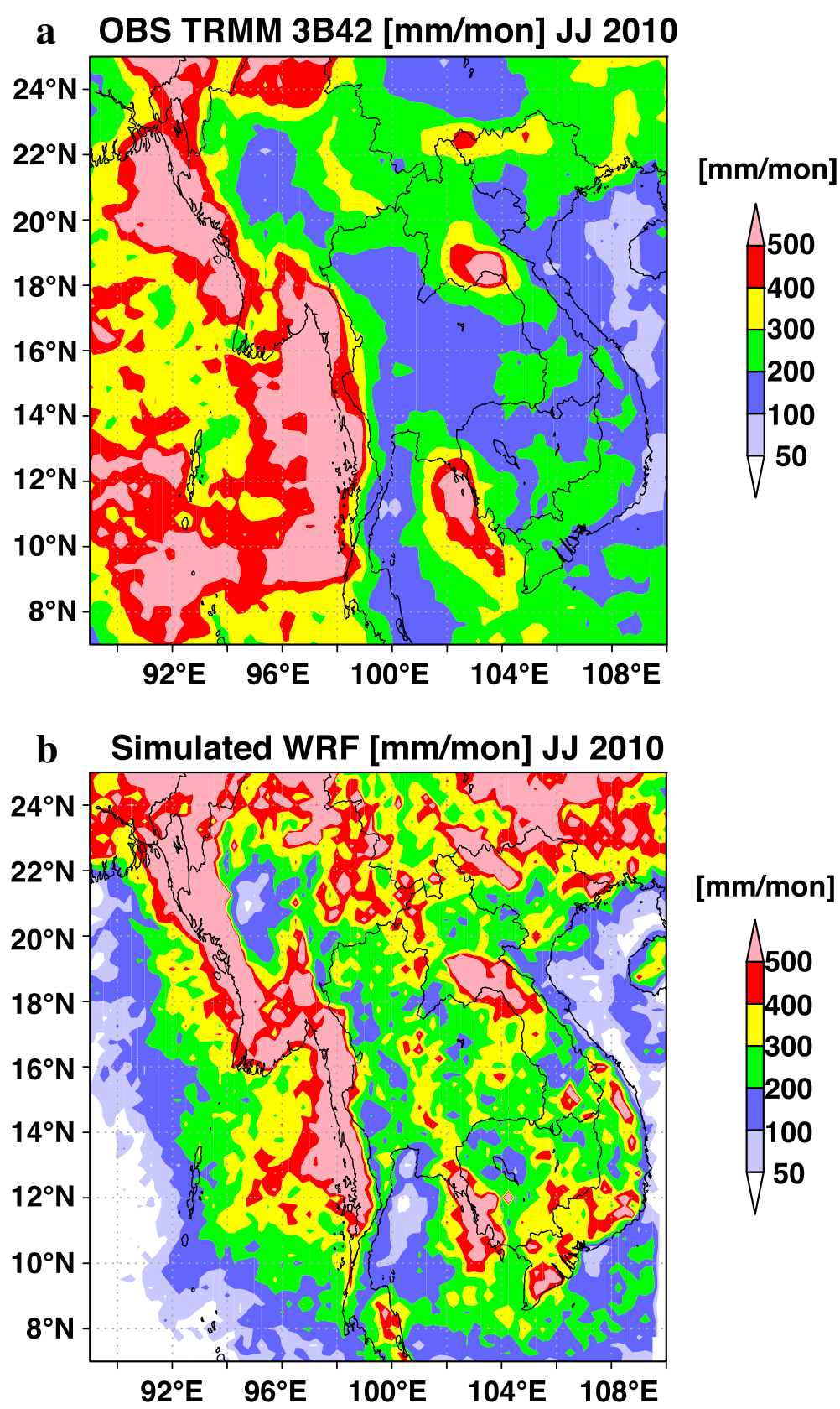

Fig. 2 a Observed (TRMM-3B42) monthly rainfall amount over the study region in June and July of 2010. b Same as the upper panel of Fig. 2 but for simulated monthly rainfall. The unit is $\mathrm{mm}$ month $^{-1}$ 


\section{Result}

\section{CTL performance}

Because this study focused on rainfall activity over the wet Asian monsoon region, we evaluated the rainfall amount for 2 months for comparison with observed data (Fig. 2).

The spatial pattern of the simulated rainfall amounts in June and July 2010 was very similar to the observed rainfall of June and July in 2010 from the TRMM3B42. Specifically, spatial peaks in rainfall amount were found along the western coast of the Indochina Peninsula and the western slopes of the Cardamom Mountains and Annamite Range in both the simulation and observations. Differences between the simulations and observations were most commonly found over higher altitude regions in mountain ranges and may have been induced by excessive condensation in the microphysics scheme over the higher altitude regions. This can be understood by the overestimation of orographic rainfall in these numerical experiments. A notable overestimation was also found over the mountainous region in the northern part of the domain, although we could not find any plausible cause for this. It should also be noted that the observations can also have biases and errors. There was a clear underestimation of the simulated rainfall over the center of the Bay of Bengal, which may be due to the lateral boundary effects of regional models. In addition, there was a clear overestimation of the estimated rainfall of TRMM-3B42, which was determined from a comparison with the more accurate TRMM-2A25 product climatology (e.g., Fig. 1 of Takahashi 2016). Nevertheless, the simulated rainfall over land regions, which was the focus of this study, was acceptable for the analysis.

\section{The impact of soil moisture on rainfall amount}

We investigated the PSMsens of rainfall amount (Fig. 3a). Overall, the PSMsens of rainfall amount shows positive and negative areas, which indicates that rainfall amount increased and decreased with increasing soil moisture. The PSMsens of rainfall amount depended on the location. A positive PSMsens of rainfall amount was observed
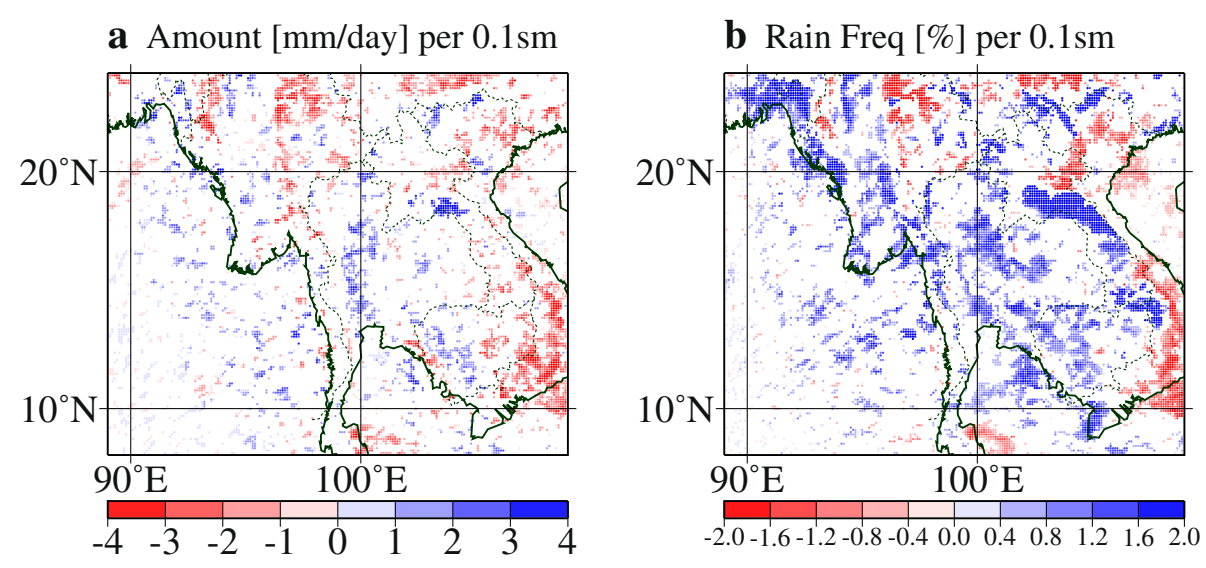

c Rain Inten $[\mathrm{mm} / \mathrm{hr}]$ per $0.1 \mathrm{sm}$

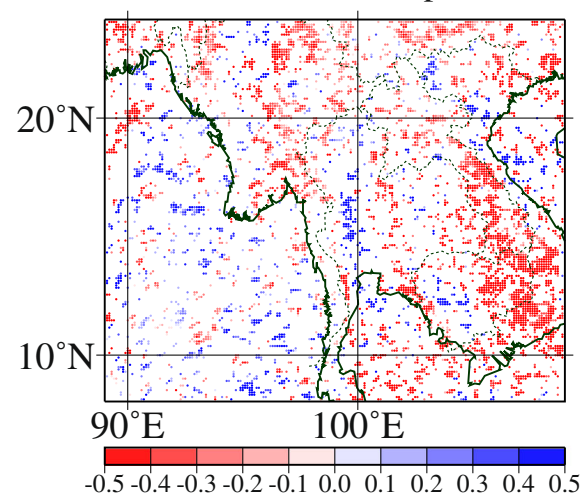

d Rain Extr $[\mathrm{mm} / \mathrm{hr}]$ per $0.1 \mathrm{sm}$

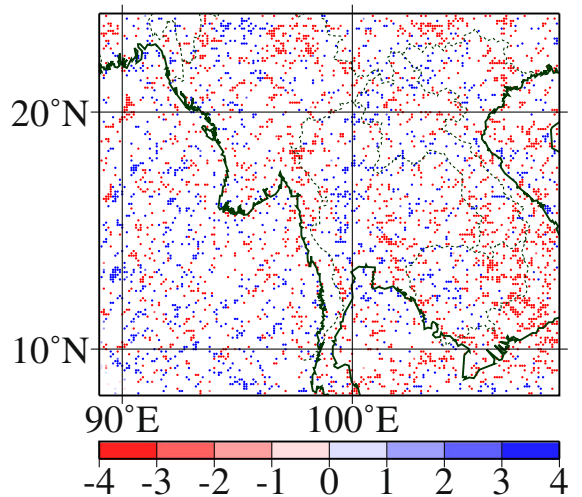

Fig. 3 Spatial map of prescribed soil moisture sensitivity (PSMsens (slope values)) of a rainfall amount, b rainfall frequency, $\mathbf{c}$ rainfall intensity, and $\mathbf{d}$ rainfall extremes as a function of the prescribed soil moisture value. All variables of rainfall characteristics were based on a 30-min time interval and 59-day data. We used the SM020, SM025, SM030, SM035, SM040, and SM045 experiments for the calculation of systematic sensitivity. The blue color indicates an increase in rainfall amount, rainfall frequency, rainfall intensity, and rainfall extremes with soil moistening. The units are $\mathrm{mm}^{\text {day }}{ }^{-1}$ per 0.1 increase in soil moisture, \% per 0.1 increase in soil moisture, $\mathrm{mm} \mathrm{h}^{-1}$ per 0.1 increase in soil moisture, and $\mathrm{mm} \mathrm{h}^{-1}$ per 0.1 increase in soil moisture, respectively 
over low, flat land, and basin-shaped valley regions, whereas a negative PSMsens was observed over mountainous regions. PSMsens signals were weak along coastal regions.

Concurrent with the changes in rainfall amount, the latent heat flux and sensible heat flux from the land surface increased and decreased over the whole calculation domain, respectively, because of the increase in soil moisture (Fig. 4). The PSMsens of latent heat flux was positive, indicating that evapotranspiration increased as a function of soil moisture, although the PSMsens values of latent heat flux from the surface differed slightly among regions. The changes in rainfall amount will be discussed in the "Discussion" section in terms of the changes of the radiation budget at the surface.

It was clear that the spatial distribution of the PSMsens of rainfall amount was not simple (Fig. 3), although the sensitivity of evapotranspiration to soil moisture was simple, being positive over the whole calculation domain (Fig. 4a). This implies that the relationship between rainfall amount and evapotranspiration is complicated and may interact with the lower atmospheric structure including the planetary boundary layer.

\section{The sensitivity of rainfall characteristics}

Changes in soil moisture can lead to subsequent changes in rainfall characteristics, such as an increase in heavy rainfall. Even if the changes in rainfall amount are relatively small, there can be changes in rainfall characteristics. To understand the changes in rainfall characteristics, we calculated the PSMsens of rainfall frequency, rainfall intensity, and rainfall extremes.

\section{Rainfall frequency}

In a series of sensitivity experiments over the wet Asian monsoon region, positive PSMsens of rainfall frequency was observed over most parts of the calculation domain (Fig. 3b). This indicates that wetter soil conditions resulted in higher rainfall frequency. The spatial pattern of positive PSMsens of rainfall frequency shows peaks over the coastal regions facing the Bay of Bengal and Gulf of Thailand, and over the inland flat plain and basinshaped valley regions close to mountain ranges, such as west of the Annamite Range. On the other hand, negative PSMsens of rainfall frequency were also observed over the limited regions, such as mountainous regions and the eastern coast of the Indochina Peninsula (having a dry season in June and July, e.g., Nguyen-Le et al. 2014).

We also produced a histogram of the PSMsens of rainfall frequency (Fig. 5a). The sensitivity values of rainfall frequency were mostly positive, which implies that the coupling of the increase in evapotranspiration and decrease in sensible heat flux resulted in an increase in rainfall frequency in this wet region.

\section{a $\operatorname{lhfx}\left[\mathrm{W} / \mathrm{m}^{\wedge} 2\right]$ per $0.1 \mathrm{sm}$}

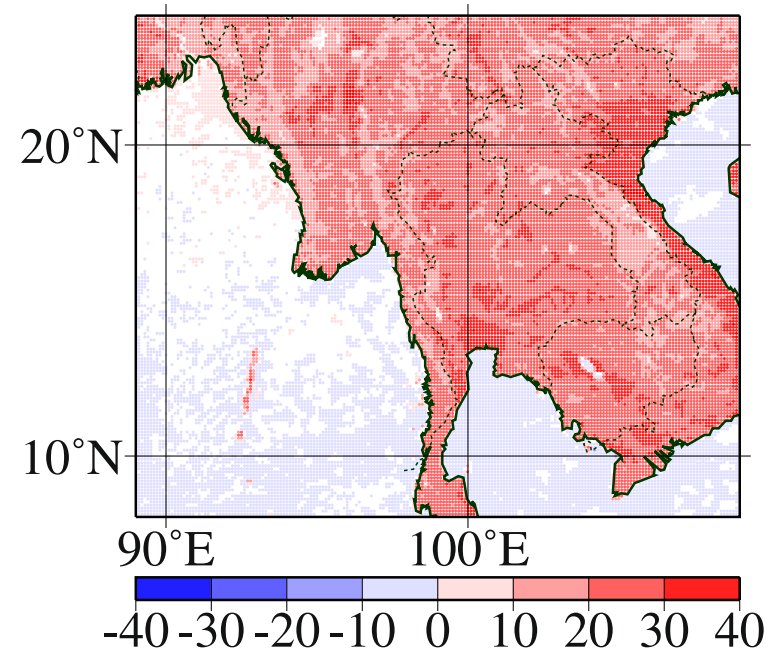

\section{b Hfx $\left[\mathrm{W} / \mathrm{m}^{\wedge} 2\right]$ per $0.1 \mathrm{sm}$}

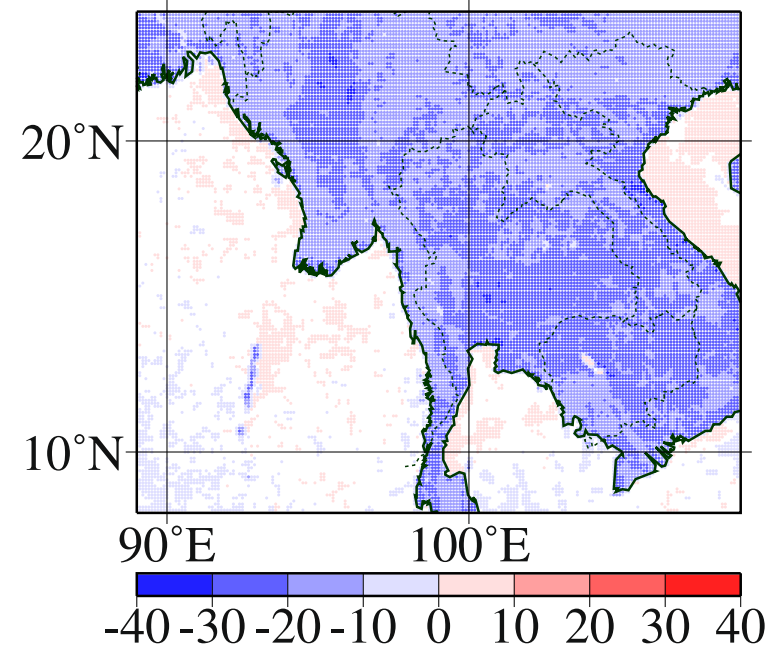

Fig. 4 Same as Fig. 3 but for $\mathbf{a}$ latent heat and $\mathbf{b}$ sensible heat fluxes. The units are $\mathrm{W} \mathrm{m}^{-2}$ per 0.1 increase in soil moisture, respectively

\section{Rainfall intensity}

We also investigated the PSMsens of rainfall intensity (Fig. 3c). A negative PSMsens of rainfall intensity was observed over most of the calculation domain, which indicates that rainfall intensity weakened due to increased soil moisture in this wet region. Some positive PSMsens of rainfall intensity were observed over basin-shaped valleys, such as Chao Phraya River Basin and the northern Vietnam regions. No clear signals were observed along the coastal regions, which can explain the weak signals in rainfall amount along the coastal region, although the signals in rainfall frequency were clear. 

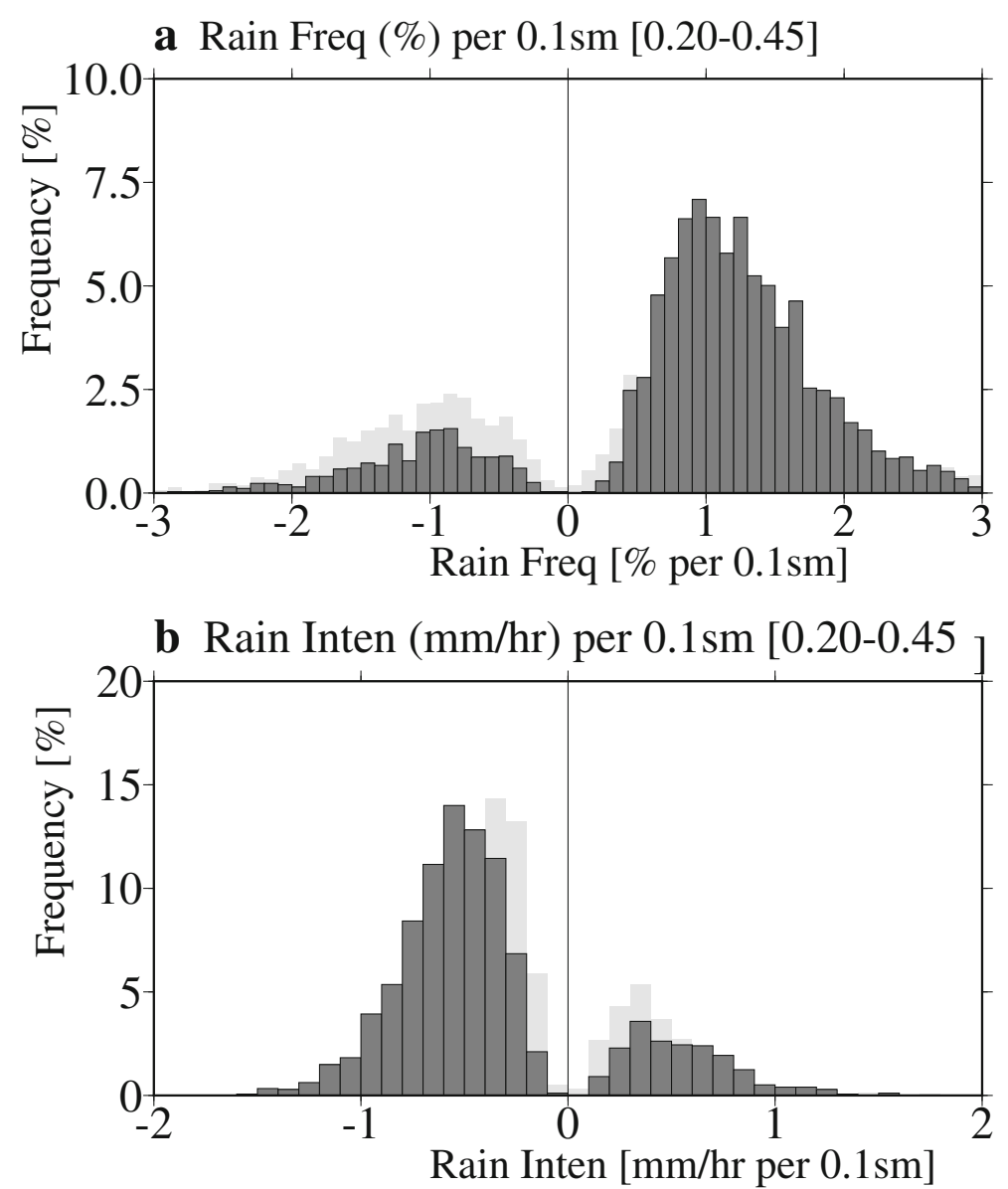

Fig. 5 Histogram of PSMsens (slope values) of a rainfall frequency and $\mathbf{b}$ rainfall intensity over the land regions. The dark shading represents the histogram for lowland regions (elevation is below $300 \mathrm{~m}$ ). The light shading denotes the histogram for all land regions. The horizontal axes in $\mathbf{a}$ and b are $\mathrm{mm} \mathrm{h}^{-1}$ per 0.1 increase in soil moisture and \% per 0.1 increase in soil moisture, respectively. The vertical axes are the frequency of each bin, expressed as a percentage

The histogram of PSMsens of rainfall intensity clearly showed that rainfall intensity mostly weakened due to increased soil moisture, with the soil moisture ranging from $0.2 \mathrm{~m}^{3} \mathrm{~m}^{-3}$ to $0.45 \mathrm{~m}^{3} \mathrm{~m}^{-3}$ (Fig. 5b). This indicated that the coupling of increased evapotranspiration and decreased sensible heat flux resulted in a weakening in rainfall intensity in this region, although the sign of the sensitivity of rainfall intensity was dependent on the location. This response of rainfall intensity to the coupling of increased evapotranspiration and decreased sensible heat flux appears opposite over the mountain ranges compared to that over lowland regions. The mechanism underlying the changes in rainfall frequency and rainfall intensity is discussed in the "Discussion" section.

\section{Rainfall extremes}

We also investigated the PSMsens of rainfall extremes (Fig. 3d). A negative PSMsens of rainfall extremes was observed over most of the calculation domain, which indicated that rainfall extremes weakened due to the increased soil moisture in this wet region. Note that the spatial pattern of the PSMsens of rainfall extremes was very similar to that of rainfall intensity (Fig. 3c). When we compared the PSMsens signals of rainfall extremes with those of rainfall intensity, the signals of PSMsens of rainfall extremes were found to be relatively scattered. It was noteworthy that the PSMsens of rainfall extremes was not similar to that of rainfall amount, but was similar to that of rainfall intensity, which implies that the sensitivity of rainfall extremes to land-surface conditions cannot be understood only from rainfall amount. Thus, it is very important to examine not only rainfall amount but also rainfall characteristics over many regions.

\section{Contribution of changes in rainfall characteristics to rainfall amount}

To understand the contribution of rainfall frequency and rainfall intensity to rainfall amount, we first expressed 
the changes in rainfall amount as a percentage. Changes in rainfall amount were found over the flat plains and valleys close to the mountain ranges, and over the mountain ranges. Increases in rainfall amount were calculated over the flat plain and valley regions. Decreases in rainfall amount were observed over the mountain ranges. As an exception, a decrease in rainfall amount was observed along the eastern coast of the Indochina Peninsula, where a climatological dry season occurs in June and July. We examined the contribution of these changes in rainfall frequency and rainfall intensity to rainfall amount.

To quantify the contribution of rainfall frequency and rainfall intensity to rainfall amount, we produced maps of PSMsens, expressed as a percentage relative to the average of a set of six runs (Fig. 6). As shown in the "The definition of rainfall characteristics" section, the changes in rainfall amount can be approximated by a linear combination of changes in rainfall frequency and rainfall intensity, which were expressed as a percentage.

Rainfall frequency tended to contribute to the increase in rainfall amount as a whole (Fig. 6b). Clear signals were observed over the flat plain and valley regions. From a quantitative perspective, the increases in rainfall frequency were of the order of several percentage points, which indicates that the changes in rainfall frequency contributed quantitatively to modifications in rainfall amount over large areas.

The changes in rainfall intensity were mostly negative (Fig. 6c). Weakening signals were mainly observed over the mountain ranges. Strengthening signals were found over the flat plains and valleys, for example Chao Phraya River Basin. From a quantitative perspective, the absolute values of the signals exceeded $15 \%$, which was larger than the changes in rainfall frequency. When the signs of rainfall frequency and rainfall intensity were different, the contribution of rainfall intensity to rainfall amount quantitatively exceeded that of rainfall frequency.

\section{Discussion}

\section{Surface energy budget and rainfall amount}

To understand the changes in rainfall amount, we investigated the PSMsens of the energy budget at the surface.

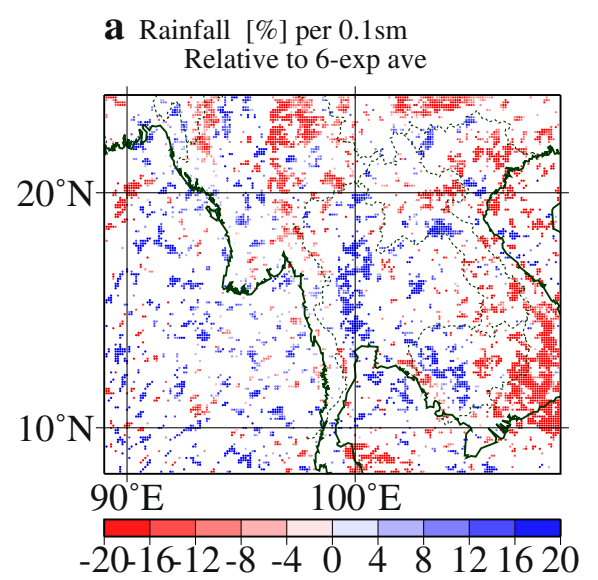

b Rain Freq [\%] per $0.1 \mathrm{sm}$ Relative to 6-exp ave.

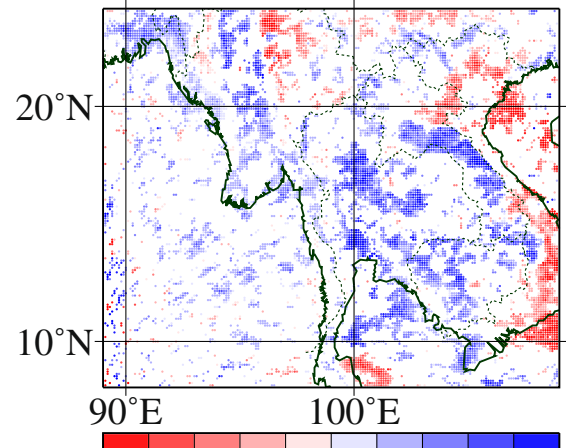

$-20-16-12-8 \quad-4 \quad 0 \quad 4 \quad 8 \quad 121620$ c Rain Inten [\%] per $0.1 \mathrm{sm}$ Relative to 6-exp ave

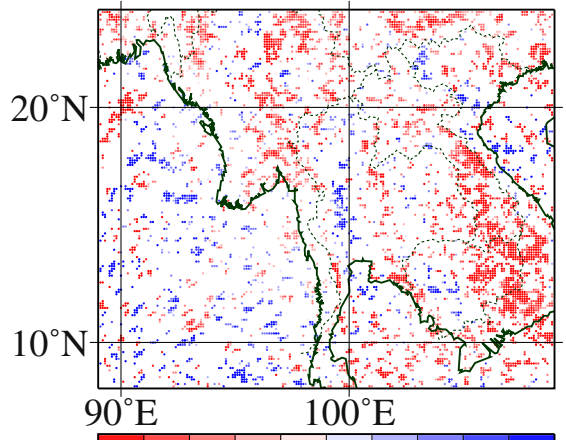

$-20-16-12-8 \quad-4 \quad 0 \quad 4 \quad 8 \quad 121620$

Fig. 6 Same as Fig. 3 but for a rainfall amount, $\mathbf{b}$ rainfall frequency, and $\mathbf{c}$ rainfall intensity, expressed as a percentage. A detailed explanation is provided in section "The definition of rainfall characteristics" 
We investigated the changes in surface energy budget derived from the law of energy conservation. The sum of the absorbed shortwave and downward longwave radiation is defined as the radiative input to the surface. The input is redistributed to upward longwave radiation (surface longwave emission), sensible and latent heat fluxes, and ground heat flux. We calculated net radiation $R n$, defined as the sum of the sensible and latent heat fluxes, and the ground heat flux (e.g., Takahashi et al. 2015).

The PSMsens of net radiation at the surface was positive over almost the entire land region (Fig. 7a). The increase in net radiation at the surface can be explained by the decrease in upward longwave radiation due to decreased land-surface skin temperature (Fig. 7b). Under wet conditions, the land-surface skin temperature is reduced due to evaporative cooling at the surface, which is also associated with changes of the Bowen ratio. At the same time, downward longwave radiation can decrease due to a decrease in surface air temperature, whereas it can increase due to an increase in water vapor in the planetary boundary layer (Fig. 7c). The decrease in upward longwave radiation at the surface due to the decrease in surface skin temperature was much larger than the increase in downward longwave radiation at the surface, which mostly increased net radiation at the surface.

When net radiation at the surface increases, the longterm and global mean rainfall amount should increase in terms of the global energy budget. However, at the regional scale, the energy balance at the surface cannot simply explain the changes in rainfall amount, which may be modified by the land-sea distribution and topography through the changes in atmospheric circulation, water vapor transport, development of the planetary boundary layer, and cloud-precipitation activity.

We focused on the regional characteristics of net radiation at the surface. Changes in the downward shortwave radiation associated with cloud changes had a large impact (Fig. 7d). The negative PSMsens of downward shortwave radiation at the surface can indicate an increase in lowlevel clouds, which have negative radiative forcing. In addition, the PSMsens of downward shortwave radiation at the surface also had clear regional characteristics.

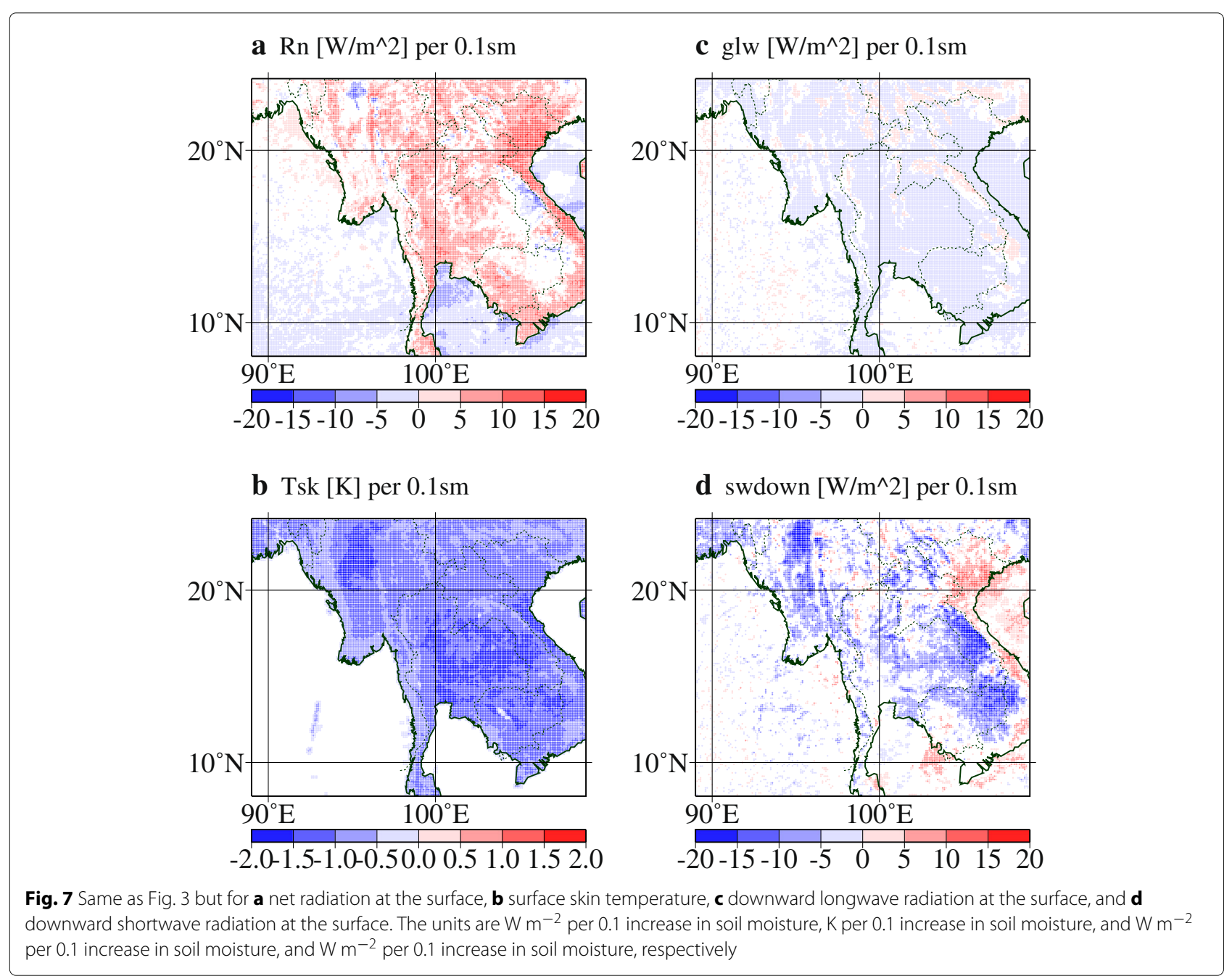


Negative spatial peaks in the PSMsens of downward shortwave radiation at the surface were calculated over the inland plains near mountain ranges, such as the eastern Korate Plateau, northern Myanmer, and a plain in Bangladesh. The following subsection discusses the changes in low-level clouds.

\section{Mechanism of changes in rainfall characteristics due to an increase in soil moisture}

This subsection discusses the coupling of the positive PSMsens of rainfall frequency and the negative PSMsens of rainfall intensity. The rainfall characteristics could be associated with the atmospheric instability (e.g., vertical structure of water vapor) and trigger of convections. An increase in sensible heat flux can induce more intense development of the planetary boundary layer, which generates convective clouds and precipitation (Ek and Holtslag 2004; Taylor and Ellis 2006; Hohenegger et al. 2009; Sugimoto and Ueno 2010; Taylor et al. 2012; Froidevaux et al. 2014). The predominant triggers of the convective systems in this region were the cold air pools of the previous convective systems (Kataoka and Satomura 2005; Takahashi et al. 2010), which were difficult to analyze statistically. On the other hand, sufficient water vapor in the lower troposphere supports the maintenance of convective systems (Satomura 2000; Kataoka and Satomura 2005; Takahashi et al. 2010; Froidevaux et al. 2014). Thus, we focused on changes in the vertical structures of hydrometeors and water vapor.

To understand the detailed vertical structure of cloud and rainfall conditions, we produced a longitude-vertical (in pressure coordinates) cross section of total hydrometeors (both liquid and solid clouds and precipitation) and specific humidity along the $18^{\circ} \mathrm{N}$ latitudinal band (Fig. 8). The vertical structure of the PSMsens of hydrometeors showed an increase in the lower troposphere and a decrease in the mid and upper troposphere (Fig. 8a). This indicated an increase in low-level clouds and a decrease in deep convections due to the increase in soil moisture. In the lower troposphere, an increase in water vapor was also distinct (Fig. 8b). Because an increase in soil moisture induced an increase in latent heat flux and a decrease in sensible heat flux, changes in vertical structure of hydrometeors and water vapor are explained by the decrease in planetary boundary layer height due to the decrease in sensible heat flux. In other words, the increases in lowlevel clouds and water vapor are due to weakening of vertical mixing. In addition, we confirmed that sensitivity in planetary boundary layer height was clearly negative to an increase in soil moisture (Fig. 9).

We also assessed the regional characteristics of the PSMsens in hydrometeors and water vapor. Figure 8 shows that the negative PSMsens of hydrometeors was very distinct above mountain ranges (around $98^{\circ} \mathrm{E}, 101^{\circ} \mathrm{E}$,

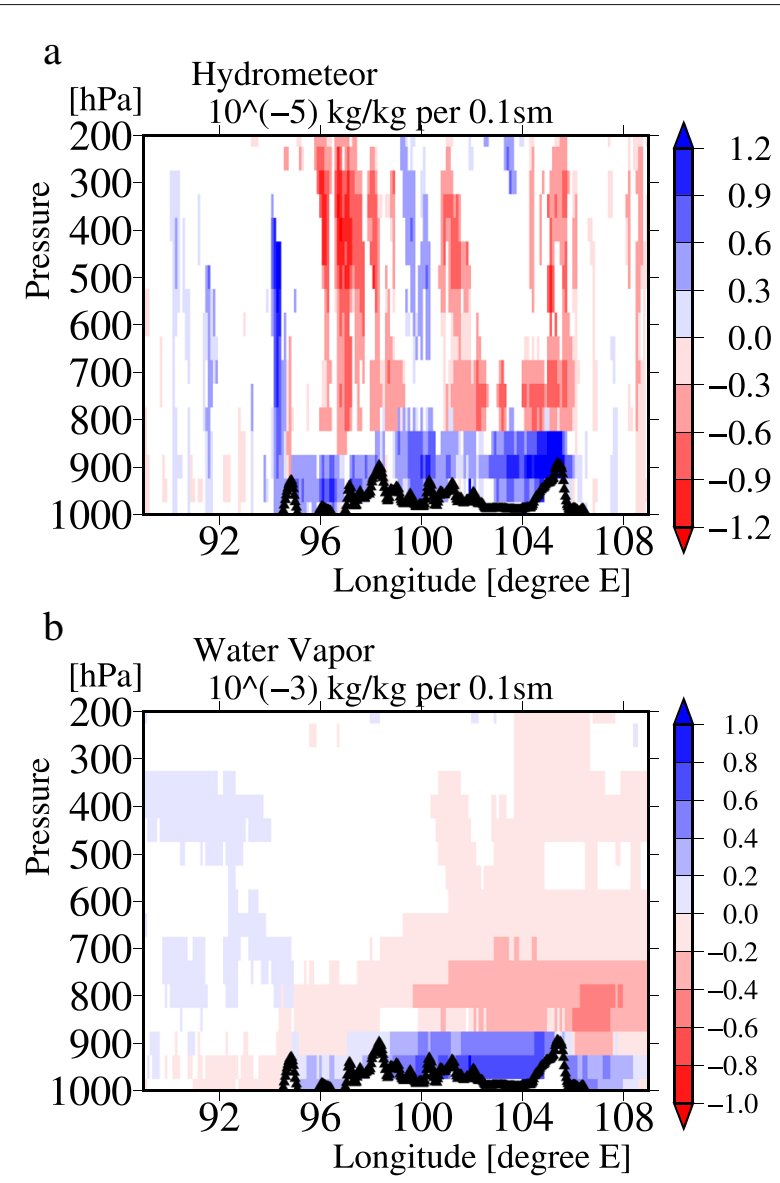

Fig. 8 Longitude-vertical (in pressure coordinates) cross section of PSMsens (slope values) in $\mathbf{a}$ hydrometeors and $\mathbf{b}$ water vapor along the $18^{\circ} \mathrm{N}$ latitudinal band. A hydrometeor was defined as the total amount of cloud and precipitations in both the liquid and solid phases. The black triangles indicate the topography along the $18^{\circ} \mathrm{N}$ latitudinal band. Both horizontal axes in $\mathbf{a}$ and $\mathbf{b}$ are longitude in ${ }^{\circ} \mathrm{E}$. The unit of hydrometeors (water vapor) is $10^{-5} \mathrm{~kg} \mathrm{~kg}^{-1}$ per 0.1 increase in soil moisture $\left(10^{-3} \mathrm{~kg} \mathrm{~kg}^{-1}\right.$ per 0.1 increase in soil moisture)

and $105^{\circ} \mathrm{E}$ ), while positive PSMsens signals were observed above the basin-shaped valleys and the flat plains (around $\left.100^{\circ} \mathrm{E}, 104^{\circ} \mathrm{E}\right)$. The major increase in low-level clouds $\left(105^{\circ} \mathrm{E}, 18^{\circ} \mathrm{N}\right)$ and minor increases in low-level clouds $\left(96^{\circ} \mathrm{E}, 18^{\circ} \mathrm{N}\right)$ and $\left(100^{\circ} \mathrm{E}, 18^{\circ} \mathrm{N}\right)$ shown in Fig. 8a were consistent with the decrease in downward shortwave radiation at the surface along the $18^{\circ} \mathrm{N}$ line (Fig. 7). This spatial feature clearly corresponded to the changes in rainfall intensity (Fig. 3c). Thus, the general changes in rainfall characteristics can primarily be explained by the changes in the planetary boundary layer height due to the changes in surface fluxes.

A weakening or decrease of deep convections due to an increase in soil moisture may also contribute to the vertical structure of hydrometeors and water vapor. Weakening of vertical and horizontal mixing by deep convections may interact with the vertical structure of 


\section{pblh $[\mathrm{m}]$ per $0.1 \mathrm{sm}$}

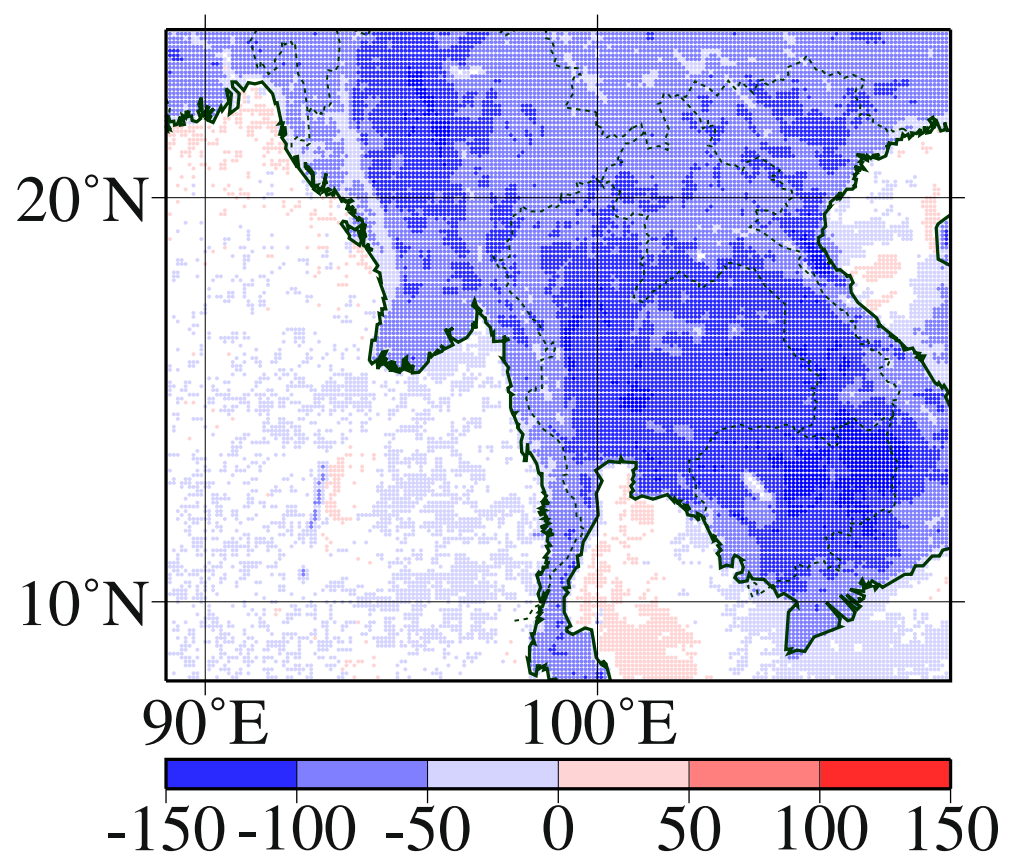

Fig. 9 Same as Fig. 3 but for planetary boundary layer height. The units are m per 0.1 increase in soil moisture

hydrometeors and water vapor. There may be a positive feedback mechanism between active deep convection and the increase in planetary boundary layer height.

We also examined changes in low-level circulations. Figure 10 shows the weakening of surface winds from ocean to land due to an increase in soil moisture (Fig. 10), which is also explained by the weakening of sensible heating over the land regions. We considered two major factors. One was the weakening of the land-ocean thermal contrast, which was obvious from Fig. 11. The other was

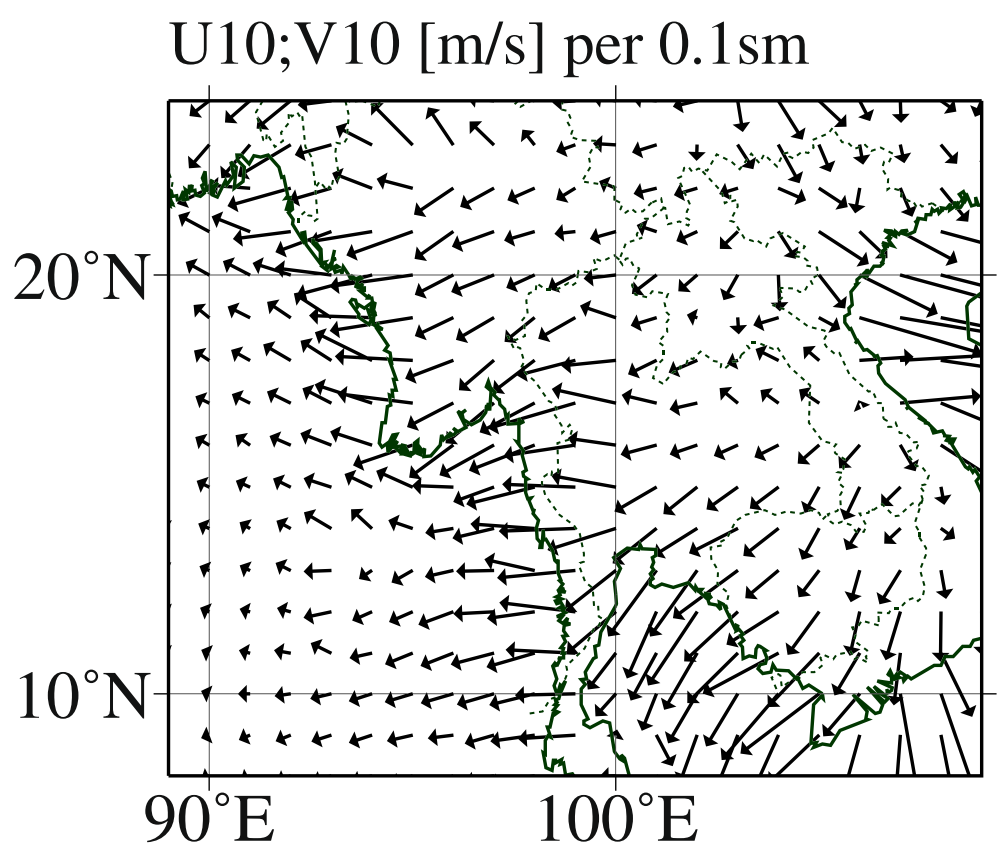

Fig. 10 Same as Fig. 3 but for winds at $10 \mathrm{~m}$ above the surface. The unit is $\mathrm{m} \mathrm{s}^{-1}$ per 0.1 increase in soil moisture 


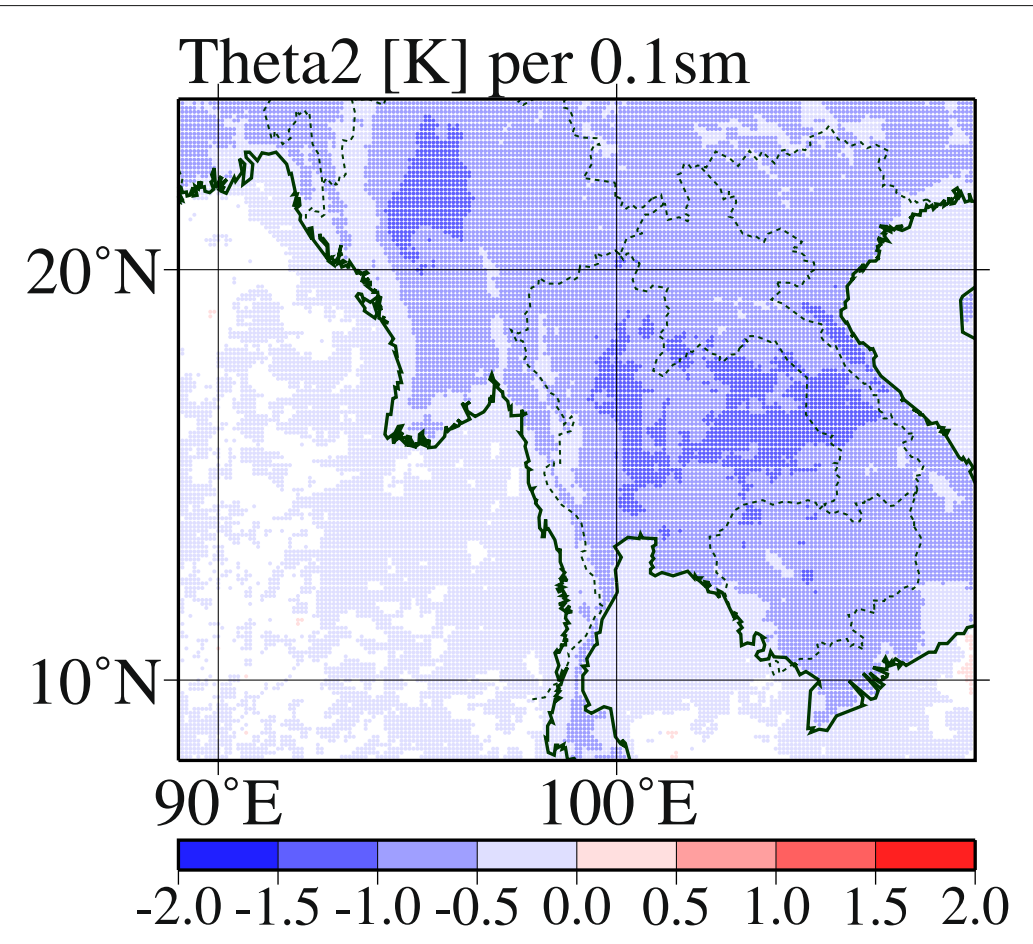

Fig. 11 Same as Fig. 3 but for potential temperature at $2 \mathrm{~m}$ above the surface. The unit is $\mathrm{K}$ per 0.1 increase in soil moisture

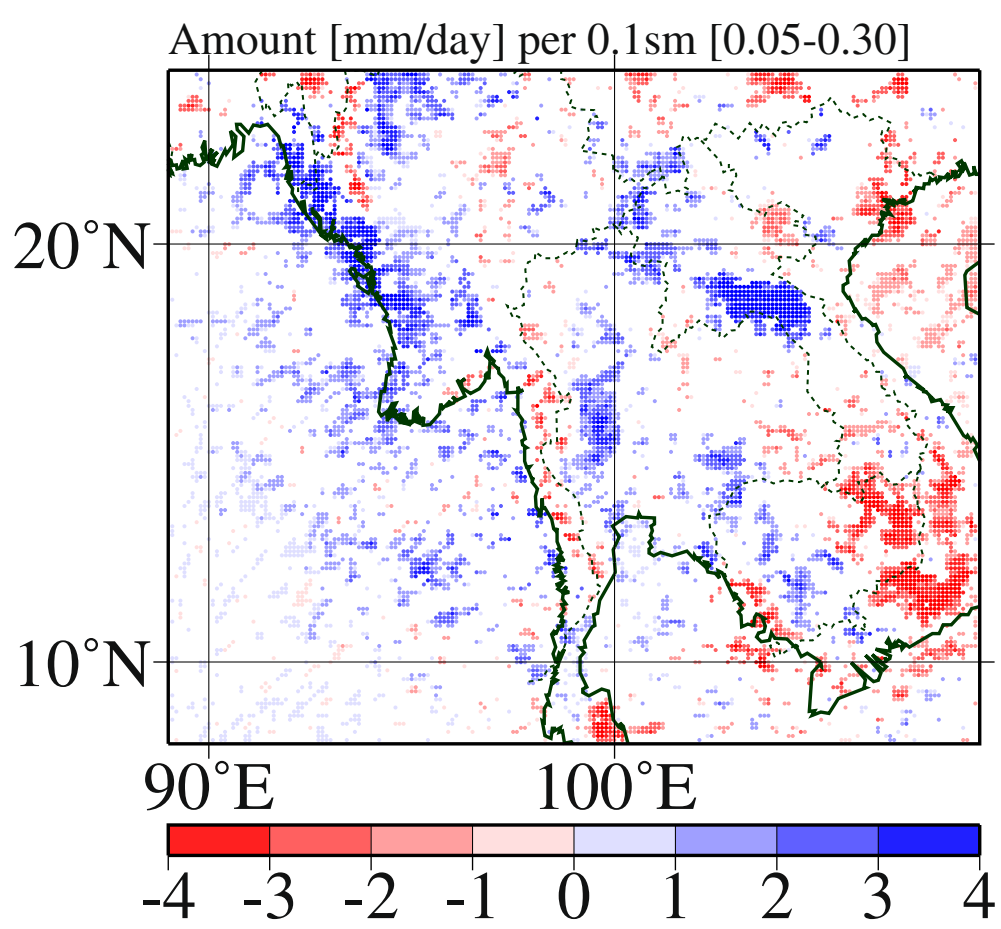

Fig. 12 Same as Fig. 3 but for rainfall amount under the drier conditions. The blue color indicates an increase in rainfall amount with soil moistening. Under the drier conditions, we used the SM005, SM010, SM015, SM020, SM025, and SM030 experiments for the calculation of PSMsens. The unit is $\mathrm{mm}$ day $^{-1}$ per 0.1 increase in soil moisture 
the decrease in the downward transport of momentum from the free troposphere into the boundary layer due to the decrease in the planetary boundary layer height (e.g., Stull 2006), which was also identified in previous studies (e.g., Takahashi et al. 2013; Dado and Takahashi 2017).

The relationship between the changes in circulation and rainfall characteristics was associated with the weakening of local circulations. However, local circulations could also be affected by rainfall and cloud activity. Thus, they strongly interact with each other, and the cause-effect relationship is not clear.

In addition, because of the weakening effect of vertical water vapor transport due to soil moistening, precipitable water over downstream regions of the Indochina Peninsula decreased. Thus, the downstream effect of soil moisture may not be negligible. However, because this may be associated with the size of the domain of the regional climate model experiments, an additional investigation of this effect is required.

\section{The sensitivity under drier conditions}

In this subsection, we discuss the PSMsens under the drier conditions in the range of $0.05 \mathrm{~m}^{3} \mathrm{~m}^{-3}$ to $0.30 \mathrm{~m}^{3} \mathrm{~m}^{-3}$, because the sensitivity can differ between dry and wet climate conditions, and between dry and wet seasons (Tuttle and Salvucci 2016; Sugimoto and Takahashi 2017). Three additional experiments were conducted. The experimental settings were basically the same, but prescribed soil moisture values were fixed at $0.05,0.10$, and $0.15 \mathrm{~m}^{3} \mathrm{~m}^{-3}$ over the whole land region during the calculation period. To calculate the PSMsens in the drier case, the six experiments with soil moisture values fixed from 0.05 to $0.30 \mathrm{~m}^{3}$ $\mathrm{m}^{-3}$ by $0.05 \mathrm{~m}^{3} \mathrm{~m}^{-3}$, were used. The wetter three experiments (SM020, SM025, and SM030) were overlapped to calculate the PSMsens under both wet and dry conditions.

The spatial pattern of the PSMsens of rainfall amount was basically the same as in the wet case (Fig. 12). In particular, the positive PSMsens of rainfall amount was clearly enhanced under the drier conditions, whereas

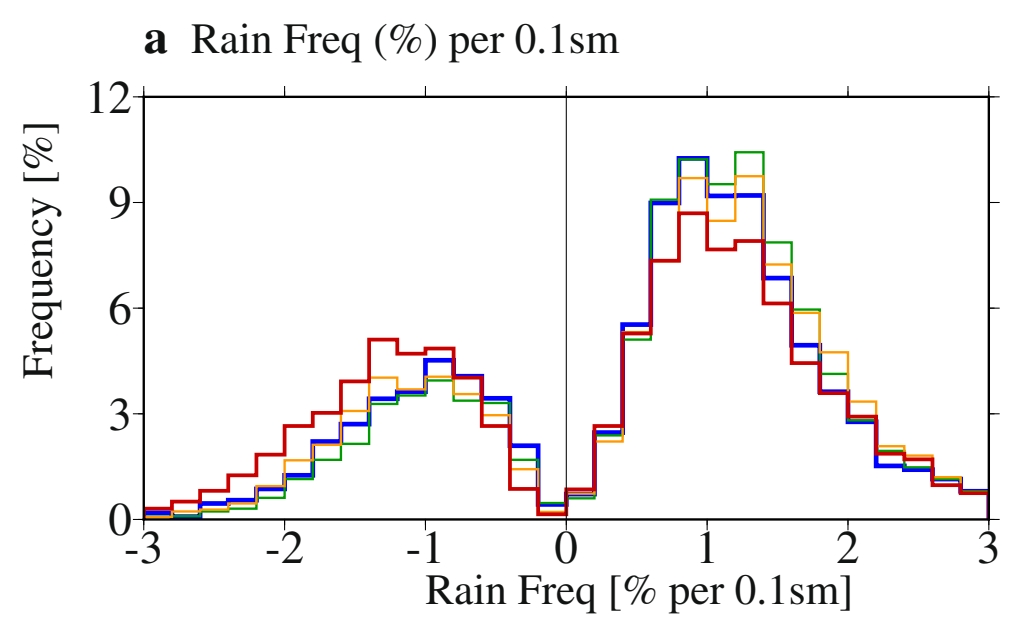

b Rain Inten (mm/hr) per $0.1 \mathrm{sm}$

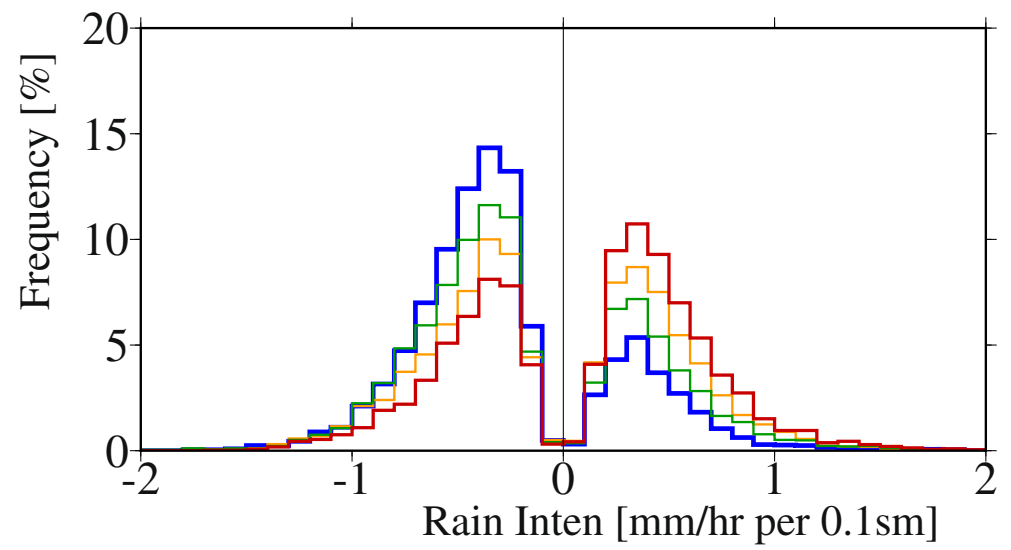

Fig. 13 Same as Fig. 5 but for PSMsens in a rainfall frequency and $\mathbf{b}$ rainfall intensity from different experiments over the land regions. The blue color indicates the same as in Fig. 5 (SM020 to SM045), green is SM015 to SM040, orange is SM010 to SM035, and red is SM005 to SM030. The horizontal axes in $\mathbf{a}$ and $\mathbf{b}$ are \% per 0.1 increase in soil moisture and $\mathrm{mm} \mathrm{h}^{-1}$ per 0.1 increase in soil moisture. The vertical axes are the frequency of each bin, expressed as a percentage 
the negative PSMsens was similar to that under the wet conditions (Fig. 12). Changes in the PSMsens of rainfall frequency and rainfall intensity are summarized in Fig. 13. All slopes were calculated based on the six experiments, although the experiments overlapped. For example, the red histogram in the figure was calculated from the experiments SM005, SM010, SM015, SM020, SM025, and SM030 (see the caption of Fig. 13).

The PSMsens of rainfall frequency had more positive values when calculated under the wetter conditions, whereas somewhat more negative values were observed under drier conditions (Fig. 13a). However, the positive PSMsens of rainfall frequency was dominant under all conditions. This result suggests that the PSMsens of rainfall frequency is mostly positive, which indicates that an increase in soil moisture contributes to an increase in rainfall frequency over this region.

For rainfall intensity, the PSMsens had more negative values under wetter conditions (Fig. 13a), while more positive values were calculated under the drier conditions. In addition, the sign of PSMsens of rainfall intensity changed according to differences in land surface wetness conditions. This suggests that rainfall intensity is suppressed under the wetter conditions due to the increase in soil moisture, whereas it may be enhanced under the drier conditions even with an increase in soil moisture. This difference may be explained by the richness of water vapor in the lower troposphere. To understand the threshold, regional characteristics, and related mechanisms, further experiments are required, including experiments over the different regions.

\section{Conclusion}

To investigate the impact of land-surface conditions (soil moisture) on rainfall characteristics over the wet Asian monsoon region, we conducted numerical experiments using a high-resolution regional climate model. Specifically, sensitivity experiments were conducted that prescribed soil moisture values of $0.2,0.25,0.3,0.35,0.4$, and $0.45 \mathrm{~m}^{3} \mathrm{~m}^{-3}$ over the whole calculation domain. We focused on not only rainfall amount, but also rainfall frequency, rainfall intensity, and rainfall extremes based on 30-min intervals. We discussed how the increase in soil moisture changes rainfall characteristics. A slope of a meteorological variable as a function of the prescribed soil moisture values was defined as the sensitivity, which is referred to as PSMsens.

The results showed that an increase in soil moisture resulted in an increase or decrease in rainfall amount depending on the location. It was noteworthy that rainfall amount did not simply increase, although evapotranspiration simply increased over the whole domain. This implies that the relationship between rainfall amount and evapotranspiration is not simple.
Rainfall frequency mostly increased due to an increase in soil moisture, which was consistent with the increased boundary layer clouds. The increase in low-level clouds was associated with increased water vapor in the lower troposphere, which was explained by an increase in latent heat flux and decrease in sensible heat flux. The decrease in sensible heat flux resulted in the weakening of vertical mixing in the lower troposphere, which also contributed to the increase in water vapor in the lower troposphere. In addition, the increase in low-level clouds was consistent with a decrease in shortwave radiation at the surface.

On the other hand, rainfall intensity and rainfall extremes decreased overall with an increase in soil moisture. The weakening of rainfall intensity and rainfall extremes was consistent with a reduction of the development of deep convections. The decrease in rainfall intensity and rainfall extremes can be due to the decrease in the planetary boundary layer height, which resulted from the decrease in sensible heat flux. The regional characteristics of the sensitivity in rainfall intensity and rainfall extremes indicated a decrease over all land regions, including mountain ranges except for 100-km-scale basinshaped valleys, for example Chao Phraya River Basin and Khorat Plateau. The regional characteristics of rainfall intensity and rainfall extremes can be associated with a weakening of development of the planetary boundary layer.

In addition, the weakening of large-scale low-level circulations at the calculation domain scale contributed to the decrease of horizontal transport in water vapor from ocean to land. This may contribute by compensating for the increase in evapotranspiration. The weakening of the large-scale low-level circulations was probably associated with the weakening of the thermal contrast between land and ocean. However, the weakening of low-level circulations could also be associated with the vertical transport of momentum due to changes in the planetary boundary layer.

\section{Abbreviations}

CTL: Control experiment; GCM: Global climate model; IPCC: Intergovernmental panel on climate change; JJ: June-July; PSMsens: Prescribed soil moisture sensitivity; RCM: Regional climate model; SMOXX: Soil moisture fixed sensitivity experiment at $0 . X X$ level; SST: Sea surface temperature; TRMM: Tropical rainfall measuring mission

\section{Acknowledgements}

We thank Dr. Shiori Sugimoto for discussing the interpretation of results. This study is partly supported by the 8th Japan Aerospace Exploration Agency (JAXA) Precipitation Measuring Mission (PMM) Project No. 309. We are also grateful for the constructive comments from the editor and reviewers in further improving this manuscript.

\section{Funding}

This work was partly supported by the "Green Network of Excellence (GRENE)" program by the Ministry of Education, Culture, Sports, Science, and

Technology (MEXT), Japan. This study is partly supported by the 8th Japan Aerospace Exploration Agency (JAXA) Precipitation Measuring Mission (PMM) Project No. 309. 


\section{Availability of data and materials}

On all experiments, please contact author (HGT) for data requests.

\section{Authors' contributions}

HGT proposed the topic and conceived and designed the study. HGT carried out the experimental study. HGT and JP analyzed the data and helped in the interpretation. HGT and JP wrote the manuscript. Both authors read and approved the final manuscript.

\section{Competing interests}

The authors declare that they have no competing interests.

\section{Publisher's Note}

Springer Nature remains neutral with regard to jurisdictional claims in published maps and institutional affiliations.

\section{Author details}

${ }^{1}$ Department of Geography, Tokyo Metropolitan University, 1-1 Minamioosawa, Hachioji, Tokyo 192-0397, Japan. ${ }^{2}$ Japan Agency for Marine-Earth Science and Technology, Yokohama 236-0001, Japan. ${ }^{3}$ Laboratoire de Météorologie Dynamique (LMD), Institut Pierre Simon Laplace (IPSL), Ecole Polytechnique, Centre National de la Recherche Scientifique (CNRS), Paris, France.

\section{Received: 20 December 2017 Accepted: 7 February 2019 Published online: 12 March 2019}

\section{References}

Chen F, Dudhia J (2001) Coupling an advanced land surface-hydrology model with the Penn State-NCAR MM5 modeling system. Part I: Model implementation and sensitivity. Mon Wea Rev 129(4):569-585

Dado JMB, Takahashi HG (2017) Potential impact of sea surface temperature on rainfall over the western Philippines. Progress Earth Planetary Sci 4(1):23

Dee D, Uppala S, Simmons A, Berrisford P, Poli P, Kobayashi S, Andrae U, Balmaseda M, Balsamo G, Bauer P, et al (2011) The ERA-Interim reanalysis: Configuration and performance of the data assimilation system. Q J R Meteorol Soc 137(656):553-597

Ek M, Holtslag A (2004) Influence of soil moisture on boundary layer cloud development. J Hydrometeorol 5(1):86-99

Froidevaux P, Schlemmer L, Schmidli J, Langhans W, Schär C (2014) Influence of the background wind on the local soil moisture-precipitation feedback. J Atmos Sci 71(2):782-799

Henderson-Sellers A, Gornitz V (1984) Possible climatic impacts of land cover transformations, with particular emphasis on tropical deforestation. Clim Chang 6(3):231-257

Hohenegger C, Brockhaus P, Bretherton CS, Schär C (2009) The soil moisture-precipitation feedback in simulations with explicit and parameterized convection. J Climate 22(19):5003-5020

Hong SY, Lim JOJ (2006) The WRF single-moment 6-class microphysics scheme (WSM6). J Korean Meteor Soc 42(2):129-151

Huffman GJ, Bolvin DT, Nelkin EJ, Wolff DB, Adler RF, Gu G, Hong Y, Bowman KP, Stocker EF (2007) The TRMM multisatellite precipitation analysis (TMPA): Quasi-global, multiyear, combined-sensor precipitation estimates at fine scales. J Hydrometeorol 8(1):38-55

lacono MJ, Delamere JS, Mlawer EJ, Shephard MW, Clough SA, Collins WD (2008) Radiative forcing by long-lived greenhouse gases: Calculations with the AER radiative transfer models. J Geophys Res 113(D13). https://doi.org/ 10.1029/2008JD009944

IPCC (2013) Climate Change 2013: The Physical Science Basis: Working Group I Contribution to the Fifth Assessment Report of the Intergovernmental Panel on Climate Change. Cambridge University Press, Cambridge, United Kingdom and New York

Jacquemin B, Noilhan J (1990) Sensitivity study and validation of a land surface parameterization using the HAPEX-MOBILHY data set. Boundary-Layer Meteorol 52(1):93-134

Janjic ZI (1994) The step-mountain eta coordinate model: Further developments of the convection, viscous sublayer, and turbulence closure schemes. Mon Wea Rev 122(5):927-945

Kataoka A, Satomura T (2005) Numerical simulation on the diurnal variation of precipitation over northeastern Bangladesh: A case study of an active period 14-21 June 1995. SOLA 1:205-208
Koster RD, Dirmeyer PA, Guo Z, Bonan G, Chan E, Cox P, Gordon C, Kanae S, Kowalczyk E, Lawrence D, et al (2004) Regions of strong coupling between soil moisture and precipitation. Science 305(5687):1138-1140

Nguyen-Le D, Matsumoto J, Ngo-Duc T (2014) Climatological onset date of summer monsoon in Vietnam. Int J Climatol 34(11):3237-3250

Ono M, Takahashi HG (2016) Seasonal transition of precipitation characteristics associated with land surface conditions in and around Bangladesh. J Geophys Res Atmos 121(19):11190-11200

Pielke RA (2001) Influence of the spatial distribution of vegetation and soils on the prediction of cumulus convective rainfall. Rev Geophys 39(2):151-177

Polcher J, Laval K (1994) The impact of African and Amazonian deforestation on tropical climate. J Hydrol 155(3-4):389-405

Reynolds RW, Rayner NA, Smith TM, Stokes DC, Wang W (2002) An improved in situ and satellite SST analysis for climate. J Climate 15(13):1609-1625

Rochetin N, Couvreux F, Guichard F (2017) Morphology of breeze circulations induced by surface flux heterogeneities and their impact on convection initiation. Q J R Meteorol Soc 143(702):463-478

Satomura T (2000) Diurnal variation of percipitation over the Indo-China Peninsula: Two-dimensional numerical simulation. J Meteor Soc Japan 78(4):461-475

Shukla J, Nobre C, Sellers P, et al (1990) Amazon deforestation and climate change. Science 247(4948):1322-1325

Skamarock WC, Coauthors (2008) A Description of the Advanced Research WRF Version 3. NCAR Technical Note. NCAR/TN-475+STR, https://doi.org/ 10.5065/D68S4MVH. https://opensky.ucar.edu/islandora/object/technotes: 500

Stull R (2006) The atmospheric boundary layer. In: Wallace JM, Hobbs PV (eds). Atmospheric Science: an Introductory Survey, 2nd edn. Elsevier Inc., USA

Sugimoto, S, Takahashi HG (2016) Effect of spatial resolution and cumulus parameterization on simulated precipitation over South Asia. SOLA 12A:7-12

Sugimoto S, Takahashi HG (2017) Seasonal differences in precipitation sensitivity to soil moisture in Bangladesh and surrounding regions. J Climate 30(3):921-938. https://doi.org/10.1175/JCLI-D-15-0800.1

Sugimoto S, Ueno K (2010) Formation of mesoscale convective systems over the eastern Tibetan Plateau affected by plateau-scale heating contrasts. J Geophys Res Atmos 115:16105

Takahashi HG (2016) Seasonal and diurnal variations in rainfall characteristics over the tropical Asian monsoon region using TRMM-PR data. SOLA 12A:22-27

Takahashi HG, Adachi SA, Sato T, Hara M, Ma X, Kimura F (2015) An oceanic impact of the Kuroshio on surface air temperature on the pacific coast of Japan in summer: Regional $\mathrm{H}_{2} \mathrm{O}$ greenhouse gas effect. J Climate 28(18):7128-7144. https://doi.org/10.1175/JCLI-D-14-00763.1

Takahashi HG, Fujinami H, Yasunari T, Matsumoto J (2010) Diurnal rainfall pattern observed by Tropical Rainfall Measuring Mission Precipitati on Radar (TRMM-PR) around the Indochina peninsula. J Geophys Res Atmos 115:07109

Takahashi HG, Fujinami H, Yasunari T, Matsumoto J, Baimoung S (2015) Role of tropical cyclones along the monsoon trough in the 2011 Thai flood and interannual variability. J Clim 28(4):1465-1476

Takahashi HG, Ishizaki NN, Kawase H, Hara M, Yoshikane T, Ma X, Kimura F (2013) Potential impact of sea surface temperature on winter precipitation over the japan sea side of japan: a regional climate modeling study. J Meteor Soc Japan 91(4):471-488. https://doi.org/10.2151/jmsj.2013-404

Takahashi HG, Yasunari T (2006) A climatological monsoon break in rainfall over Indochina-A singularity in the seasonal march of the Asian summer monsoon. J Clim 19(8):1545-1556

Takahashi HG, Yoshikane T, Hara M, Takata K, Yasunari T (2010) High-resolution modelling of the potential impact of land surface conditions on regional climate over Indochina associated with the diurnal precipitation cycle. Int J Climatol 30(13):2004-2020

Takahashi HG, Yoshikane T, Hara M, Yasunari T (2009) High-resolution regional climate simulations of the long-term decrease in September rainfall over Indochina. Atmos Sci Lett 10(1):14-18

Takata K, Saito K, Yasunari T (2009) Changes in the Asian monsoon climate during 1700-1850 induced by preindustrial cultivation. Proc Natl Acad Sci 106(24):9586-9589

Taylor CM (2015) Detecting soil moisture impacts on convective initiation in Europe. Geophys Res Lett 42(11):4631-4638 
Taylor CM, de Jeu RA, Guichard F, Harris PP, Dorigo WA (2012) Afternoon rain more likely over drier soils. Nature 489(7416):423-426

Taylor CM, Ellis RJ (2006) Satellite detection of soil moisture impacts on convection at the mesoscale. Geophys Res Lett 33(3):03404

Taylor CM, Parker DJ, Harris PP (2007) An observational case study of mesoscale atmospheric circulations induced by soil moisture. Geophys Res Lett 34(15):15801

Tuttle S, Salvucci G (2016) Empirical evidence of contrasting soil moisture-precipitation feedbacks across the United States. Science 352(6287):825-828

\section{Submit your manuscript to a SpringerOpen ${ }^{\circ}$} journal and benefit from:

- Convenient online submission

Rigorous peer review

- Open access: articles freely available online

- High visibility within the field

- Retaining the copyright to your article

Submit your next manuscript at $\boldsymbol{\nabla}$ springeropen.com 